\title{
Catecholamines and conditioned blocking: effects of ventral tegmental, septal and frontal 6-hydroxydopamine lesions in rats*
}

\author{
R.D. Oades, J.-M. Rivet, K. Taghzouti, M. Kharouby, H. Simon and M. Le Moal \\ Psychobiologie des Comportements Adaptatifs, I.N.S.E.R.M. 259, Bordeaux (France)
}

(Accepted 5 August 1986)

Key words: Dopamine; Noradrenaline; Ventral tegmental area; Septum; Frontal cortex;

Attention; Conditioned blocking; Active avoidance

\begin{abstract}
The performance of rats on the conditioned blocking test of learned inattention was measured in a two-way shuttle avoidance task after sham and dopamine (DA)-depleting lesions of the frontal cortex, septum and ventral tegmental area (VTA). Animals were trained on two sessions with tone and/or light as conditioned stimuli. One group was trained with both stimuli on both sessions. A second group was trained on the first session with one stimulus and on the second with both stimuli. The blocking of conditioning to the added stimulus (b) was tested by presenting the stimuli ( $a$ and $b$ ) separately and measuring the blocking ratio (avoidance to b/a $+b$ ) and response latencies. No deficits were recorded on tests of sensory and motor ability. The VTA group alone showed a hyperlocomotor response to apomorphine treatment and did not acquire the avoidance response. The appearance of blocking in the septal group was delayed until the end of the test session. Blocking was mildly attenuated in the frontal group. DA levels were depleted by about $80 \%$ and noradrenaline (NA) levels by, respectively, 20 and $50 \%$ in frontal and septal areas. This suggests that the level of DA activity or the balance between the activity of DA and NA in frontal and limbic regions can contribute to efficient associative conditioning and/or the normal ability of rats not to attend to a redundant stimulus.
\end{abstract}

\section{INTRODUCTION}

In animals as diverse as rodents and primates damage to the septum and frontal cortex is associated (inter alia) with impairments of selective information processing 16,22,23,28,31,32,47,65. Depletion of dopamine (DA), a major neuroregulator in these areas largely found in terminals of neurons that project from the ventral tegmental area (VTA) ${ }^{78}$, affects both learning ${ }^{9,24.69}$ and adjunctive behavior (e.g. schedule-induced licking or drinking) ${ }^{62,63.67,69}$. But specific tests for a selective attention deficit after DA depletion have not been used, except in studies of the basal ganglia ${ }^{13,73,76}$. Therefore we used one of these tests, conditioned blocking performance, after DA deple- tion with 6-hydroxydopamine (6-OHDA) in the frontal cortex, septum and VTA to investigate the contribution of mesolimbic and mesocortical DA activity to selective information processing.

Conditioned blocking belongs to a group of 'learned inattention' tasks where performance has been claimed to reflect the function of selective attention mechanisms ${ }^{30,41}$. If an animal is trained to respond to the simultaneous presentation of two stimuli from the start of conditioning, it will respond to the presentation of either stimulus alone at the end of conditioning. In a blocking task if one stimulus (e.g. a light) predicts reinforcement (e.g. a footshock) and has started to control response (e.g. avoidance), then when a second stimulus is presented along with the

\footnotetext{
* Some of these results were communicated in preliminary form at the E.B.B.S.-S.F.E.C.A. workshop, Strasbourg, 1985 and the Australian Neuroscience Meeting, Perth, 1986.

Correspondence: R.D. Oades. Present address: Department of Physiology, Flinders Medical Centre, Bedford Park, S.A. 5042, Australia.
} 
first after the start of training (e.g. tone and light), even if it is perfectly correlated with reinforcement, the second stimulus will not become associated with reinforcement. In this example an animal tested with the tone alone will tend not to show an avoidance response. That is to say the association between tone and footshock has been 'blocked'. An attenuation of blocking (conditioning to the second stimulus) is operationally called an impairment of attention.

Impaired performance on tasks of learned inattention has been reported after non-specific damage and electrical stimulation of the septum and hippocampus ${ }^{1,12,43,57-59,66,72}$ (contrast ref. 21). Evidence from pharmacological interventions suggests that these impairments may arise from interference with the innervation of these or related areas by biogenic amines such as acetylcholine ${ }^{45,71}$, serotonin ${ }^{74,75}$ and possibly noradrenaline (for refs. 14, 39, 40; against refs. $2,19,80$ ). Treatments that release DA or induce DA supersensitivity are also claimed to impair performance on such tasks $s^{15,73,76,83}$. But the only area studied postmortem for changes of DA activity was the $n$. accumbens. Up to now an attentional impairment as a result of abnormal activity in the mesofrontal or mesoseptal DA system has only been inferred from performance on alternation tasks ${ }^{9,69}$, holeboard learning ${ }^{48,49}$ and increases of behavior collateral to task performance (e.g. rearing and turning) ${ }^{54,69}$.

\section{MATERIALS AND METHODS}

Data from 40 male Sprague-Dawley rats (260$320 \mathrm{~g}$ ) divided between 4 treatment and two learning conditions are considered. Animals were housed individually in a climate-controlled room on a 12-h lightdark cycle $\left(22^{\circ} \mathrm{C}, 08.00-20.00 \mathrm{~h}\right.$ light $)$ with food and water ad libitum. All animals were weighed and handled daily.

\section{Treatment}

Two weeks prior to training each rat received a bilateral infusion of 6-OHDA ( $1 \mu \mathrm{l}$ containing $4 \mu \mathrm{g}$, calculated as base) or its vehicle $(0.2 \mathrm{mg} / \mathrm{ml}$ ascorbic $\mathrm{acid} / \mathrm{saline}$ solution) under chloral hydrate anesthesia $(4 \%, 10 \mathrm{ml} / \mathrm{kg}$ ) over $4 \mathrm{~min}$ to the VTA (toothbar $+5 \mathrm{~mm}$ : $3.2 \mathrm{~mm}$ posterior to the bregma, 0.5 lateral to the sinus, 8.8 ventral from the skull), septum (1.5 $\mathrm{A}, 0.7 \mathrm{~L}, 5.8 \mathrm{~V}$ ) and frontal cortex (3.3 and 3.8 A, 0.5
$\mathrm{L}, 4.0 \mathrm{~V})$. The 30 -gauge cannulas were left in place after infusion. Animals were pretreated with 20 $\mathrm{mg} / \mathrm{kg}$ desmethylimipramine (Pertofran, Ciba-Geigy) to protect noradrenergic (NA) terminals.

After 30 days animals were decapitated, the brains were dissected rapidly on ice and the samples stored at $-87^{\circ} \mathrm{C}$. On dissection, coronal slices were taken at $1-2 \mathrm{~mm}^{27,34}$ corresponding to Konig-Klippel coordinates 11,050-10,300 (frontal cortex, F), 10,3008,380 (n. accumbens, Acc) and 8380-6300 (neostriatum, STR and septum, S). Samples from each side of the brain were analyzed by high-performance liquid chromatography (HPLC) (Perkin-Elmer, 5- $\mu$ C-18 reverse phase) with glassy carbon electrochemical detection (Bioanalytical Systems, LC4B, $720 \mathrm{mV}$ ). After sonication and alumina separation samples were run in $0.1 \mathrm{M}$ phosphate buffer $(\mathrm{pH} 4)$ at $3200 \mathrm{psi}$ and $1 \mathrm{ml} / \mathrm{min}$. Quantification was non-linear below $20 \mathrm{pg}$. Animals with less than $50 \%$ bilateral or with unilateral DA depletion were eliminated from the analysis of data.

\section{Testing apparatus}

Locomotor activity was measured in a circular corridor $12 \mathrm{~cm}$ wide and $170 \mathrm{~cm}$ long, equipped with 4 photocell beams, and counts were recorded automatically from a print-out counter located outside the testing room ${ }^{33}$.

Two-way active avoidance conditioning took place in a metal shuttle box (Campden, $49 \times 21 \times 20 \mathrm{~cm}$ ) with a $2-\mathrm{cm}$ electrified hurdle in the middle and floor bars $(1.5 \mathrm{~cm}$ apart) that could be electrified by a scrambled $1.0-\mathrm{mA} \mathrm{AC}$ current. A light stimulus $(60$ lux) was located on each side and a loudspeaker for the delivery of the sound stimulus $(900 \mathrm{~Hz}, 86 \mathrm{~dB})$ on one side. Two such boxes were placed in neighboring air conditioned chambers (constant 66-dB white noise) in a sound-attenuated room. The program for delivery of the conditioned stimuli (CS) (max. duration $10 \mathrm{~s}$ followed by unconditioned stimulus (US), max. $15 \mathrm{~s}$ ) was controlled by a PDP 8 Digital computer. Stimuli were switched off by avoidance $(5 \mathrm{~s})$ or escape responses which were automatically recorded. Interstimulus intervals varied randomly in 15-s steps from 15 to $90 \mathrm{~s}$ (mean $30 \mathrm{~s}$ ).

Tests for sound and shock sensitivity were conducted in the shuttle box and the response to stronglight illumination in a box with two compartments ( 25 
$\times 23 \times 40 \mathrm{~cm}$ ) connected by an $8 \times 8 \mathrm{~cm}$ opening with a $150 \mathrm{~W}$ bulb $35 \mathrm{~cm}$ over one side ${ }^{3,10}$. Three tests for akinesia were conducted on an open bench (latency to remove forepaws from a 3-cm block; latency to rotate on a $60^{\circ}$ inclined grid; latency to move 4 paws after release from cupped hands ${ }^{18,21}$ ).

\section{Training and testing}

The 3 tests for akinesia were performed immediately prior to operation and again just before the start of postoperative conditioning. Measures of latency were taken for each test with a minimum of $2 \mathrm{~min}$ between each trial. The median value for each test was taken for analysis. On the postoperative test two VTA animals with latencies consistently longer by a factor of 10 were eliminated and not tested further.

Tests for sensitivity to the US and CS were performed the day after tests for conditioning (postoperative day 19 or 24 , depending on initial weight gains). Average thresholds for flinch, jump and vocalization responses were determined on ascending and descending series of 8 current intensities $(0.05-1.0$ $\mathrm{mA}$ ) presented to the animal confined to one side of the shuttle box ${ }^{11}$. Sensitivity to sound was measured in the shuttle box by presenting 4 trials each at 6 levels of sound intensity $(86,83,79,72,68 \mathrm{~dB})$ in 3 descending/ascending series of intensities. Only the usual CS intensity was reinforced. The latency of avoidance, escape, or in the case of non-conditioned
VTA animals, behavioral responses (e.g. look up, move, rear) were recorded. Responsiveness to light was recorded in terms of the latency to escape from and return to the light compartment of the two-chamber box in which the animal had been carefully placed facing away from the entrance to the dark side. Separate measures for entry latencies with two and 4 paws were taken.

The conditioning procedure, modified after Crid$\mathrm{er}^{15}$, lasted 6 days starting on postoperative day 12 or 17 (depending on weight) (Table I). Animals were brought to the test room each day in their home cage. Two animals were tested at the same time. The one would be given the blocking procedure, the other would be a learning control. On day 1 of the procedure both animals were given 1.5 -h exploration experience of the shuttle box without CS or US. On days 2 and 3 one animal started training with the single CS ' $a$ ' whilst the other continued with free exploration of the box. Both received training with the compound CS 'ab' (light and tone) on days 4 and 5. The learning criterion was $8 / 10$ avoidances on 3 successive blocks of 10 trials. On attaining criterion the session would be terminated to avoid the effects of overtraining. The progress of a session was monitored outside the test room on the computer printout. There was a maximum of 100 trials/day and a minimum of 100 trials in 2 days. On day 6 the blocking test followed an initial session of 20 reminder trials. The test consisted

TABLE I

Summary: behavioural training and testing (conditioned blocking)

\begin{tabular}{|c|c|c|c|c|c|c|}
\hline & \multirow[b]{2}{*}{ Day 1} & \multicolumn{2}{|l|}{ Stage 1} & \multicolumn{2}{|l|}{ Stage 2} & \multirow{2}{*}{$\frac{\text { Stage } 3}{\text { Day } 6}$} \\
\hline & & Day 2 & Day 3 & Day 4 & Day 5 & \\
\hline $\begin{array}{l}\text { Blocking } \\
\text { group }\end{array}$ & $\begin{array}{l}\text { Explore/ } \\
\text { habituation }\end{array}$ & $\begin{array}{l}\text { CS a } \\
100 \text { trials } \\
\text { reinforced }\end{array}$ & $\begin{array}{l}\text { CS a } \\
100 \text { trials } \\
\text { reinforced or } \\
\text { to criterion }\end{array}$ & $\begin{array}{l}\mathrm{CS} \text { ab } \\
100 \text { trials } \\
\text { reinforced or } \\
\text { to criterion } \\
(\min 50)\end{array}$ & $\begin{array}{l}C S \text { ab } \\
100 \text { trials } \\
\text { reinforced or } \\
\text { to criterion } \\
(\min 50)\end{array}$ & $\begin{array}{l}C S \text { ab } \\
20 \text { trials reinforced } \\
\text { then } \\
\mathrm{CS} \mathrm{a} \\
20 \text { trials } \\
\text { non-reinforced } \\
\mathrm{CS} \mathrm{b} \\
20 \text { trials } \\
\text { non-reinforced } \\
\text { and }\end{array}$ \\
\hline $\begin{array}{l}\text { Control } \\
\text { group }\end{array}$ & $\begin{array}{l}\text { Explore/ } \\
\text { habituation }\end{array}$ & $\begin{array}{l}\text { Explore and } \\
\text { habituation }\end{array}$ & $\begin{array}{l}\text { Explore and } \\
\text { habituation }\end{array}$ & $\begin{array}{l}C S a b \\
100 \text { trials } \\
\text { reinforced }\end{array}$ & $\begin{array}{l}\text { CS ab } \\
100 \text { trials } \\
\text { reinforced or } \\
\text { to criterion } \\
(\min 50)\end{array}$ & $\begin{array}{l}\mathrm{CS} \text { ab } \\
12 \text { trials reinforced } \\
\text { sequence: } a, b \text {, } \\
a, a b, b, a, b, a b\end{array}$ \\
\hline
\end{tabular}


of 20 non-reinforced presentations of each stimulus alone, interspersed with reinforced presentations of the compound CS (e.g. a, b, a, ab, b, a, b, ab, a).

Biochemical data were analyzed with Student's $t$ test. Behavioral data were subjected to analysis of variance for related samples (e.g. pre- and postoperative tests; Friedman) or for independent samples (e.g. conditioned blocking; Kruskal-Wallis) before post hoc paired testing (Mann-Whitney), unless otherwise stated.

\section{RESULTS}

Animals were not tested until they had regained their preoperative weight. There was a 12- or 17-day recovery period as some animals with VTA lesions were slow to regain weight.

\section{Motor tests}

The latencies of response on the 3 tests of akinesia for animals that continued with the conditioning procedure ( $n=10$ per group) are shown in Table II. Taking into account preoperative response latencies there were no consistent differences between the groups across tests $\left(\mathrm{df}=7, \chi^{2}=11, P 0.1>0.2\right)$.

\section{Stimulus sensitivity}

There were no consistent differences between groups across the current thresholds that elicited vocalization, jump or flinch responses (e.g. flinch; mean current threshold \pm S.E.M.: C, $0.28 \pm 0.08$; VTA, $0.33 \pm 0.07 ; \mathrm{S}, 0.24 \pm 0.03$; and F, $0.24 \pm 0.05$ $\mathrm{mA}$ ).

Avoidances, or behavioral responses in the VTA
TABLE III

Mean latency (s) to exit and return to an illuminated chamber ( \pm S.E.M.)

Four lesion groups; $C$, sham control; VTA, ventral tegmental area; S, septum; F, frontal cortex. See text for further details.

\begin{tabular}{|c|c|c|c|c|}
\hline & \multicolumn{4}{|l|}{ Group } \\
\hline & $\bar{C}$ & $V T A$ & $S$ & $F$ \\
\hline Exit & $16.8 \pm 4.7$ & $42.5 \pm 9.3$ & $12.0 \pm 2.9$ & $38.8 \pm 9.7$ \\
\hline Return & $37.2 \pm 6.1$ & $31.0 \pm 8.8$ & $65.6 \pm 27.9^{*}$ & $39.5 \pm 16.8$ \\
\hline
\end{tabular}

* Includes one example at maximum latency (recording period $300 \mathrm{~s})$.

group (e.g. stop and look), were recorded at the lowest sound sensitivity of $68 \mathrm{~dB}$ (white noise $66 \mathrm{~dB}$ ) for all animals except one from the VTA group, one septal and two sham-control animals. Further analysis of response latencies revealed no consistent differences between groups. A measure of the reactivity to light was provided by the latencies to leave and return to a brightly illuminated chamber (Table III), recorded after avoidance conditioning. Neither an analysis for the 4 lesion groups $\left(\chi^{2}=5.4\right)$ nor one taking into account the different conditioning experience ( $\mathrm{df}=7$, $\chi^{2}=2.6$ ) showed there to be any intergroup differences.

\section{Learning}

No animal with VTA damage acquired a conditioned avoidance. Several animals in this group showed but one avoidance response in 200 trials. There were no significant differences in the rate of avoidance acquisition between animals with sham,

\section{TABLE II}

Akinesia tests: mean latency (s) to remove forepaws from a block (forepaw), to rotate $180^{\circ}$ on an inclined grid (rotation) and to initiate locomotion (move) pre-and postoperatively ( \pm S.E.M.)

Four lesion groups: C, sham control; VTA, ventral tegmental area; S, septum; F, frontal cortex. See text for further details.

\begin{tabular}{|c|c|c|c|c|c|c|c|c|}
\hline & \multicolumn{8}{|l|}{ Group } \\
\hline & \multicolumn{2}{|l|}{$C$} & \multicolumn{2}{|l|}{$V T A$} & \multicolumn{2}{|l|}{$S$} & \multicolumn{2}{|l|}{$F$} \\
\hline & Pre & Post & Pre & Post & Pre & Post & Pre & Post \\
\hline Forepaw & $1.8 \pm 0.3$ & $2.7 \pm 0.6$ & $1.7 \pm 0.2$ & $2.9 \pm 0.6$ & $1.3 \pm 0.2$ & $2.2 \pm 0.9$ & $1.8 \pm 0.8$ & $1.6 \pm 0.3$ \\
\hline Rotation & $11.5 \pm 2.3$ & $7.4 \pm 0.9$ & $8.2 \pm 1.8$ & $10.3 \pm 1.8$ & $8.2 \pm 1.9$ & $6.0 \pm 1.2$ & $10.7 \pm 2.3$ & $6.4 \pm 1.2$ \\
\hline Move & $4.8 \pm 1.0$ & $3.2 \pm 0.5$ & $5.7 \pm 0.8$ & $4.5 \pm 1.1$ & $2.7 \pm 0.6$ & $1.6 \pm 0.5$ & $3.8 \pm 0.6$ & $2.1 \pm 0.5$ \\
\hline
\end{tabular}



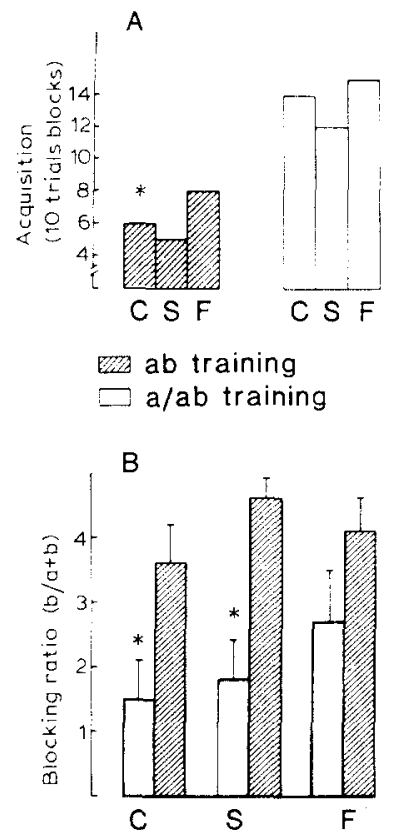

Fig. 1. A: mean number of blocks of 10 trials to attain $8 / 10$ avoidance responses to a single CS (shaded column) or the compound light/tone CS (open column) in a two-way shuttle box. B: mean ( \pm S.E.M.) avoidance responses to $\mathrm{CS} \mathrm{b/a+b}$ (blocking ratio) after training in the blocking condition (CS $\mathrm{a} / \mathrm{ab}$ : (open column)) or in the normal learning condition with $\mathrm{CS}$ ab (shaded column). $n=10$ per group, 5 per condition. C, sham control; S, septal group; F, frontal group: ${ }^{*} P<0.05$.

septal or frontal lesions, but acquisition was facilitated for animals presented with the compound CS 'ab' with respect to those presented with only the tone or the light at the start of conditioning $\left(\chi^{2}=16.8, P<\right.$ 0.01 ). Posthoc testing supported this at the $5 \%$ level (Fig. 1A).

\section{Blocking}

Analysis of the blocking ratio (avoidance responses to $b / a+b)$ showed an interaction between lesion and experience ( $\left.\mathrm{df}=5, \chi^{2}=13.6, P<0.02\right)$. The differences related to the blocking and not the control condition where post hoc analysis confirmed that blocking was attenuated in the frontal $(U=6)$ but present in the septal $(U=0, P<0.001)$ and sham control group $(U=4, P<0.05)$ (Fig. 1B).

As animals made more escape than avoidance responses to CS presentations, an analysis of response latency made more use of the data available. Analysis of the latency of response to the first 3 presentations of CS 'b' $\left(\chi^{2}=12.04, P<0.05\right)$ showed that the

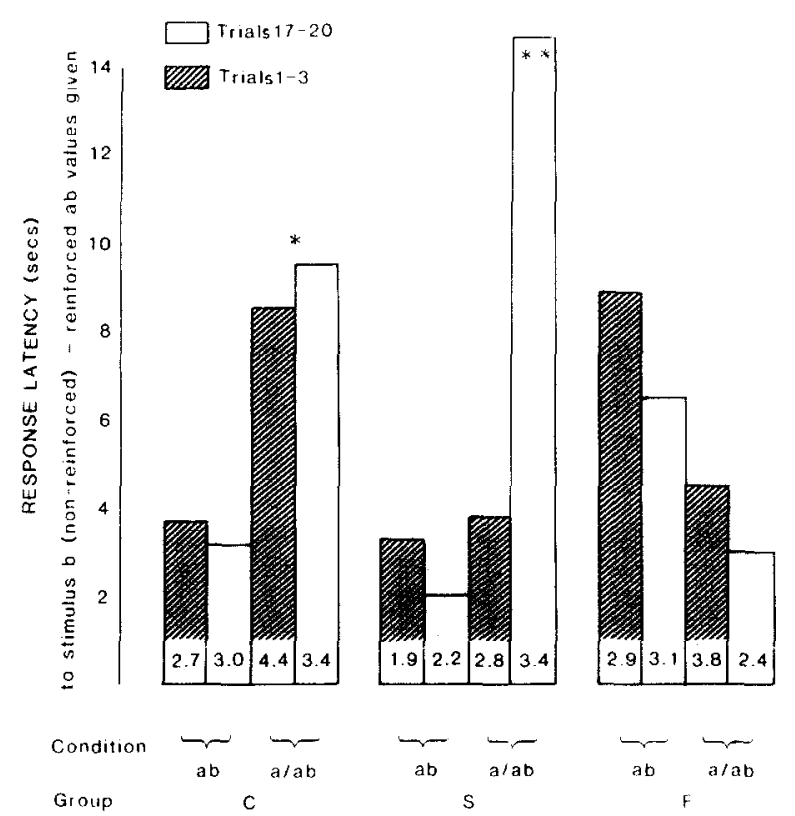

Fig. 2. The mean response latencies for the first (1-3) and last $(17-20) 3$ test presentations of the non-reinforced CS b were calculated for animals trained in the blocking ( $a / a b)$ and learning control conditions $(\mathrm{ab})$. The medians of these latencies are shown for control (C), septal (S) and frontal (F) animal groups in each condition. In each column are shown the response latencies to the most recent 3 reinforced presentations of CS ab. Median of the mean test avoidance latencies to CS a after ab and $\mathrm{a} / \mathrm{ab}$ training were: $\mathrm{C}, 3.4,4.6 ; \mathrm{S}, 3.6,4.4$; and $\mathrm{F}, 4.7,4.8 \mathrm{~s}$. ${ }^{*} P<0.05,{ }^{* *} P<0.02$.

septal group responded faster than controls $(U=4, P$ $<0.05$ ). Blocking was attenuated. Differences on the last 3 presentations $\left(\chi^{2}=11.13, P<0.05\right)$ were due to longer latencies (233\%) shown by the septal group $(U=2, P<0.02)$. All animals with septal lesions increased response latency across presentations $(P<0.03$ Sign test $)$ and hence showed blocking at the end of the test (Fig. 2). This analysis confirmed blocking in the sham-control group $(U=4, P<0.05)$ and its attenuation in the frontal group $(U=7)$.

For comparison data were obtained as a control for overlearning. Four animals were presented with the same protocol (e.g. sham lesion, 4 training sessions), but received 3 times the number of CS ' $a$ ' as CS ' $a b$ ' presentations, (mean blocking ratio $0.27 \pm 0.06$; median of trials $1-3$ mean latency, $5.3 \mathrm{~s}$, trials $17-20$, $9.3 \mathrm{~s})$.

\section{Biochemistry}

Severe depletion of DA and its metabolite DOPAC were recorded in all projection regions of 


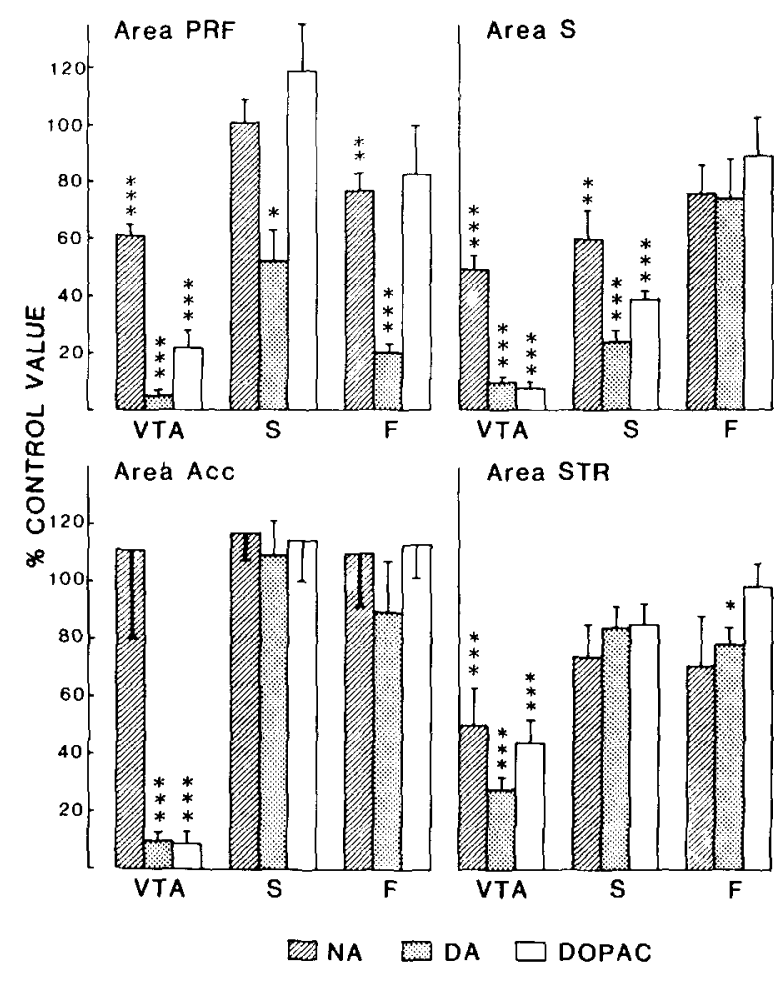

Fig. 3. Mean percentage of control values for noradrenaline (NA), dopamine (DA) and its metabolite DOPAC in the medial prefrontal cortex (PRF), septum (S), n. accumbens (Acc) and anterior neostriatum (STR) are shown in the 4 panels. These levels were measured after 6-OHDA or control vehicle treatment of frontal (F), septal (S) and ventral tegmental areas (VTA) (horizontal axis). $n=10$ per group. Control values for areas PRF, S, Acc and STR were, respectively: NA, 0.25, 1.01, $0.55,0.49$; DA, $0.10,0.55,5.78,10.16$; and DOPAC, 0.04, $0.16,1.78,1.85 \mathrm{ng} / \mathrm{g} \mathrm{w}$. wt.

the VTA after VTA-6-OHDA treatment (Fig. 3). Treatment of the septum and frontal cortex with 6OHDA reduced DA levels by about $80 \%$ whilst utilization rates (DOPAC:DA) remained high. Outside the area of treatment decreases of the level of DA were noted in the frontal area after septal treatment $(48 \%)$ and in the anterior neostriatum after treatment of the frontal cortex (22\%). Noradrenaline levels fell after VTA-6-OHDA treatment in the neostriatal, septal and frontal areas and after septal-6OHDA treatment in the septum (ca. 50\%).

\section{Locomotion}

There were no major differences between treatment groups on 24-h counts of locomotor activity in the circular corridor. Subsequent apomorphine treatment $(0.2 \mathrm{mg} / \mathrm{kg}$ in $0.3 \mathrm{ml}$, s.c. $)$ resulted in hyperlocomotion in the VTA group alone. Over the $60 \mathrm{~min}$ following treatment locomotion increased 10-fold. These levels were 5 times higher than those shown by other groups (Table IV).

\section{DISCUSSION}

The degree of depletion of DA after 6-OHDA treatment of the VTA, septum and frontal cortex is comparable with previous reports ${ }^{27,29,69,79}$. DA receptor supersensitivity as indicated by the hyperlocomotor response to apomorphine treatment was recorded only for the VTA group ${ }^{33}$. Thus the main results of this experiment were: (1) that animals with VTA-6-OHDA lesions failed to acquire a two-way shuttle avoidance response; (2) 6-OHDA lesion of the septum or frontal cortex did not affect the rate of avoidance acquisition; (3) during testing animals with septal-6-OHDA damage developed blocking after initially showing attenuated blocking; and (4) lesion of the frontal cortex with 6-OHDA attenuated blocking. The results will be discussed in this order.

TABLE IV

Locomotor activity in a circular corridor: mean photocell counts per hour measured over $24 \mathrm{~h}$ after $3 . \mathrm{h}$ habituation (CON) followed by apomorphine-induced locomotion recorded for $1 \mathrm{~h}$ (APO:0.2 $\mathrm{mg} / \mathrm{kg}$ s.c.) ( \pm S.E.M.)

Four lesion groups $(n=10)$ : C, sham control; VTA, ventral tegmental area; S, septum; F, frontal cortex.

\begin{tabular}{|c|c|c|c|c|}
\hline & \multicolumn{4}{|l|}{ Group } \\
\hline & $\bar{C}$ & $V T A$ & $S$ & $F$ \\
\hline $\mathrm{CON}$ & $99.3 \pm 10.8$ & $133.7 \pm 19.1$ & $114.1 \pm 12.1$ & $94.1 \pm 6.7$ \\
\hline $\mathrm{APO}$ & $203.9 \pm 54.5$ & $1302.8 \pm 232^{*}$ & $305.6 \pm 66.5$ & $217.2 \pm 37.3$ \\
\hline
\end{tabular}


Rats with VTA-6-OHDA lesions did not learn the shuttle avoidance task ${ }^{53}$. An opposite result obtained after radiofrequency lesion ${ }^{36}$ may be attributable to damage of non-DA neurons and differences in the training protocol. Different effects on locomotor behavior have been found to follow non-specific electrolytic and 6-OHDA lesions of the VTA ${ }^{33}$. Thus as the VTA group showed a hyperlocomotor response to apomorphine our results may be attributable to denervation supersensitivity in one or more of the VTA-projection regions. Depletion of DA in the neostriatum and $\mathrm{n}$. accumbens, but neither alone, has been reported to impair acquisition of a one-way avoidance $^{34}$. Since DA levels were reduced in both structures in the present study (Fig. 3) it is tempting to relate the two learning impairments. However NA levels were also depleted in projection regions after VTA lesion and may have contributed to the behavioral changes recorded.

Lesion of ascending DA fibers with 6-OHDA does not impair simple visual discriminations ${ }^{56,69}$. But there are many reports that systemic treatment with DA antagonists or intraventricular/nigral 6-OHDA impairs the acquisition of conditioned avoidance, but not escape responses (for review see ref. 5). This may be a result of impaired incentive learning, as has been reported for animals treated with pimozide ${ }^{6}$ or impaired cognitive processing suggested to be necessary for alternation tasks ${ }^{69}$.

Active avoidance acquisition may be facilitated after electrolytic lesion of the septum ${ }^{28,46}$ or mildly impaired after non-specific prefrontal damage ${ }^{42}$. But we found no differential rate of acquisition after DA depleting lesions or sham-operations in these areas. This is an essential condition for the study of learned inattention during task acquisition ${ }^{15}$ and one that has not been easy to achieve in similar studies of the result of NA depletion ${ }^{61}$.

Control tests show that the differences found on the conditioned blocking tests cannot be easily attributed to altered perception of the CS or US intensity or motor activity. There were no differences between groups on 3 measures of akinesia (after initial elimination of two VTA animals), on the flinch/jump current sensitivity threshold nor on sound sensitivity. We were unable to arrange a psychophysical test for light sensitivity, but in the two-compartment light/ dark box which has been used to measure fearfulness and reactivity to a bright light ${ }^{3,10}$ there was no overall difference between groups and light-approach latencies were similar.

After septal-6-OHDA treatment animals showed no attenuation of blocking according to the ratio of avoidances to $b / a+b$ over 20 trials. We are not aware of studies of the effect of lesion damage of the septum on conditioned blocking. But damage to the hippocampus has been reported to attenuate blocking $^{57,58,70}$. It is therefore of interest to note that depletion of septal DA has been reported to stimulate hippocampal activity as measured by choline uptake ${ }^{24}$. Therefore, with respect to the function of one of the most important septal efferent pathways, the overall result demonstrating blocking is consistent with previous studies.

However, successful blocking has been reported after hippocampal damage with only two stimulus presentations on the first test ${ }^{25}$ (contrast ref. 59). Although the protocols differ we compared initial and final response latencies in our 20-trial test. Initial short response latencies to the added stimulus (b) on trials 1-3 were followed by much longer escape latencies on trials 17-20. There was a change from attenuated to normal or exaggerated blocking. Was this a result of DA depletion? DA levels were mildly depleted in frontal regions after septal-6-OHDA treatment. Whilst this might affect blocking, frontal depletion must be more complete to affect delayed alternation performance ${ }^{69}$. Further much greater depletions of NA than were found in the present study (max. 20\%) do not affect blocking ${ }^{51,61}$. Thus it is likely that the initial attenuation of blocking was related to either DA levels or an imbalance between catecholamine levels in the septum.

Rats with non-specific septal damage are often hyper-reactive ${ }^{28}$ yet do not make use of supplemental stimuli in learning ${ }^{4,17,77}$. A parsimonious explanation for our results is that initially the septal-6-OHDA rats escaped in response to a marked stimulus change (hyper-reactive) but in the absence of reinforcement rapidly developed blocking to the superfluous stimulus (focussing of attention) ${ }^{17,28}$. But we would emphasize that this result needs to be replicated and the effect of a change of stimulus protocol investigated before conclusions are drawn.

Lesion of the frontal cortex with 6-OHDA did not affect NA levels in any region examined and, outside 
the frontal cortex, mildly lowered DA levels (20\%) in the anterior striatum. Thus the effects of the lesion may be attributed to either DA depletion or the imbalance between levels of NA and DA. Such an imbalance in the frontal cortex may bring about small increases of locomotion ${ }^{55}$. But increased locomotion did not result in increased crossovers in the shuttle box. Indeed there was a relatively long response latency to CS $b$ in the learning control condition (ab, Fig. 2). We have no simple explanation for this. The difference was not due to fatigue as avoidance latencies were elicited for both reinforced presentations of $\mathrm{CS}$ ab and non-reinforced presentations of CS a (Fig. 2). The use of a visual stimulus for animals with damage that could affect the frontal eye field might result in overshadowing by the sound stimulus. However there is no evidence for this in the animals trained in the blocking condition nor was a change of responsiveness recorded in the light/dark box.

One possible interpretation for the mild attenuation of blocking seen after frontal-6-OHDA damage is that DA depletion enhances the associability of CS $b$ analogous to the effect of overtraining animals to $\mathrm{CS}$ a. Four intact animals were tested with a 3-fold increase of the number of trials with CS a before exposure to $\mathrm{CS}$ ab. The blocking ratio showed a $60 \%$ attenuation which parallels the change from control to frontal levels. It would seem worthwhile investigating this parallel further. From the present results we would propose that frontal and accompanying neostriatal DA depletion ${ }^{67}$ (Fig. 3) affect information processing ${ }^{37}$ and that this deficit interacts with experiential factors to impair stimulus associability. Fus$\operatorname{ter}^{23}$ has proposed 3 major functions for the frontal cortex: short-term memory; preparatory set; and the control of interference from alternative stimuli, as

\section{REFERENCES}

1 Ackil, J.R., Melgren, R.L., Halgren, C. and Frommer, S.P., Effects of CS preexposure on avoidance learning in rats with hippocampal lesions, J. Comp. Physiol. Psychol., 69 (1969) 739-747.

2 Archer, T., Mohammed, A.K. and Jarbe, T.U.C., Latent inhibition following systemic DSP 4: effects due to presence and absence of contextual cues in taste aversion learning, Behav. Neural Biol., 38 (1983) 287-307.

3 Aulich, D., Escape vs exploratory activity: an interpretation of rat behavior in the open field and a light-dark pref- seen in the performance of delayed alternation and matching tasks. Our results support the idea ${ }^{9,69}$ that frontal catecholaminergic activity may affect the third of these functions, namely the influence of alternative stimuli in the control of the organization of behavioral responses.

In conclusion, 6-OHDA lesion of the septum and frontal cortex can affect early information processing in different ways. In the septal group blocking developed after repeated presentation of redundant stimuli. An attenuation of blocking after frontal depletion may reflect changes in associative learning and/or the regulation of attention. This study has not addressed the question of whether these changes are due to a depletion of DA alone or to a relative imbalance between DA and NA levels. Recent clinical and psychophysiological studies have shown the importance of cognitive symptoms in conditions such as schizophrenia $^{8,26,50,84}$ and Parkinson's disease ${ }^{35,81,82}$. Some of these symptoms are similar to those associated with dysfunction of the frontal lobe $\mathrm{e}^{7,38,50}$ and nuclei associated with the septum ${ }^{20,64,68}$. Catecholaminergic dysfunction in human septal and frontal areas may contribute to attentional deficits in hyperactive syndromes $^{52}$ and psychoses ${ }^{44}$. Further studies of the effect of DA depletion on performance in overshadowing and learned inattention paradigms would be useful to confirm and extend the present results.

\section{ACKNOWLEDGEMENTS}

R.D.O. is grateful to the Fyssen Foundation and for a senior N.A.T.O. fellowship for financial support. We thank Dr. R. Dantzer for logistical support and Drs. A. Raab and A. Crocker for discussion. erence test, Behav. Proc., 1 (1976) 153-164.

4 Beatty, W.W. and Carbone, C.P., Septal lesions, intramaze cues and spatial behavior in rats, Physiol. Behav., 24 (1980) 675-678.

5 Beninger, R.J., The role of dopamine in locomotor activity and learning, Brain Res. Rev., 6 (1983) 173-196.

6 Beninger, R.J. and Phillips, A.G., The effect of pimozide on the establishment of conditioned reinforcement, Psychopharmacology, 68 (1980) 147-153.

7 Bowen, F.P., Behavioral alterations in patients with basal ganglia lesions. In M.D. Yahr (Ed.), The Basal Ganglia, Raven Press, New York, 1976, pp. 169-180. 
8 Braff, D.L. and Sacuzzo, D.P., The time course of information processing deficits in schizophrenia, Am. J. Psychiat., 142 (1985) $170-174$

9 Brozoski, T.J., Brown, R.M., Rosvold, H.E. and Goldman, P.S., Cognitive deficit caused by regional depletion of dopamine in prefrontal cortex of rhesus monkey, Science, 205 (1979) 929-931.

10 Bruneau, N., Simon, H. and Le Moal, M., Dark-light emergence at two different times of the nycthermal cycle in the four and twelve week old rat, Behav. Proc., 5 (1980) $281-285$.

11 Bures, J., Buresova, O. and Huston, J., Techniques and Basic Experiments for the Study of Brain and Behavior, 2nd edn., Elsevier, Amsterdam, 1983, 326 pp.

12 Burton, N.A. and Toga, A.W., Successive discrimination performance improves with increasing numbers of stimulus preexposures in septal rats, Behav. Neural Biol., 34 (1982) $141-151$.

13 Carli, M., Evenden, J.L. and Robbins, T.W., Depletion of unilateral striatal dopamine impairs initiation of contralateral actions and not sensory attention, Nature (London), 313 (1985) 679-682.

14 Caza, P., Noradrenergic influences on blocking: interactions with development, Pharmacol. Biochem. Behav., 21 (1984) 9-17.

15 Crider, A., Solomon, P.R. and McMahon, M.A., Disruption of selective attention in the rat following chronic D-amphetamine administration: relationship to schizophrenic attention disorder, Biol. Psychiat., 17 (1982) 351-361.

16 Crowne, D.P., The frontal eye field and attention, Psychol. Bull., 93 (1983) 232-260.

17 Donovick, P.J., Burright, R.G., Sikorszky, R.D., Stamato, N.J. and MacLaughlin, W.M., Cue elimination effects on discrimination behavior of rats with septal lesions, Physiol. Behav., 20 (1978) 71-78.

18 Dunnett, S.B. and Iversen,S.D., Sensorimotor impairments following localized kainic acid and 6-hydroxydopamine lesions of the neostriatum, Brain Research, 248 (1982) $121-127$.

19 Everitt, B.J., Robbins, T.W., Gaskin, M. and Fray, P., The effects of lesions to ascending noradrenergic neurons on discrimination learning and performance in the rat, Neuroscience, 10 (1983) 397-410.

20 Farley, I.J., Price, K.S. and Hornykiewicz, O., Dopamine in the limbic regions of the human brain: normal and abnormal. In E. Costa and G. Gessa (Eds.), Advances in Biochemical Psychopharmacology, Raven Press, New York, 1977, pp. 57-64.

21 Flicker, C., Dean, R.L., Watkins, D.L., Fisher, S.K, and Bartus, R.T., Behavioral and neurochemical effects following neurotoxic lesions of a major cholinergic input to the cerebral cortex in the rat, Pharmacol. Biochem. Behav., 18 (1983) 973-981.

22 Fuster, J.M., Behavioral electrophysiology of the prefrontal cortex, Trends Neurosci., 7 (1984) 408-414.

23 Fuster, J.M., The prefrontal cortex, mediator of cross-temporal contingencies, Human Neurobiol., 4 (1985) 169-179.

24 Galey, D., Durkin, T., Sifakis, G, and Jaffard, R., Improvement of spontaneous and acquired spatial behaviour after lesion of septal dopaminergic afferents in mice: possible relationship with hippocampal cholinergic activity, C.R. Acad. Sci. (Paris), 299 (1984) 681-686.

25 Garrud, P., Rawlins, J.N.P., Mackintosh, N.J., Goodall, G., Cotton, M. and Feldon, J., Succesful overshadowing and blocking in hippocampectomized rats, Behav. Brain Res., 12 (1984) 39-53

26 Gjerde, P.F., Attentional capacity dysfunction and arousal in schizophrenia, Psychol. Bull., 93 (1983) 57-72.

27 Herman, J.-P., Guilloneau, D.. Dantzer, R., Scatton, B., Semerdjian-Rouquier, C. and Le Moal, M. Differential effects of inescapable footshocks and of stimuli previously paired with inescapable footshocks on dopamine turnover in cortical and limbic areas of the rat, Life Sci., 30 (1982) 2207-2214

28 Isaacson, R.L., The Limbic System, 2nd edn., Plenum Press, New York, 1982, 327 pp

29 Joyce, E.M., Stinus, L. and Iversen, S.D., Effect of injections of 6-OHDA into either nucleus accumbens septi or frontal cortex on spontaneous and drug-induced activity, Neuropharmacology, 22 (1983) 1141-1145.

30 Kamin, L.J., Predictability, surprise, attention and conditioning. In B.A. Campbell and R.M. Church (Eds.), Punishment and Aversive Behavior, Appleton-CenturyCrofts, New York, 1969.

31 Knight, R.T., Hillyard, S.A., Woods, D.L. and Neville, H.J., The effects of frontal cortex lesions on event-related potentials during auditory selective attention, Electroencephalogr. Clin. Neurophysiol., 52 (1981) 571-582.

32 Kolb, B., Functions of the frontal cortex of the rat: a comparative review, Brain Res. Rev., 8 (1984) 65-98.

33 Koob, G.F., Sinus, L. and Le Moal, M., Hyperactivity and hypoactivity produced by lesions to the mesolimbic dopamine system, Behav. Brain Res., 3 (1981) 341-359.

34 Koob, G.F., Simon, H., Herman, J.-P. and Le Moal, M., Neuroleptic-like disruption of the conditioned avoidance response requires destruction of both mesolimbic and nigrostriatal systems, Brain Research, 303 (1984) 319-329.

35 Lees, A.J. and Smith, E., Cognitive deficits in the early stages of Parkinson's disease, Brain, 106 (1983) 257-270.

36 Le Moal, M., Cardo, B. and Stinus, L., Influence of ventral mesencephalic lesions on various spontaneous and conditioned behaviors in the rat, Physiol. Behav., 4 (1969) $567-573$

37 Leviel, V., Kerny, C., Barberis, C., Guilbert, B. and Daudet, F., Blockade by frontocortical lesion of reciprocal regulation between the two nigrostriatal dopaminergic pathways, Neuroscience, 13 (1984) 53-59.

38 Levin, S., Frontal lobe dysfunctions in schizophrenia - II. Impairments of psychological and brain functions, $J$. Psychiat. Res., 18 (1984) 57-72.

39 Lorden, J.F., Rickert, E.J. and Berry, D.W., Forebrain monoamines and associative learning. I. Latent inhibition and conditioned inhibition, Behav. Brain Res., 9 (1983) $181-199$.

40 Lorden, J.F., Rickert, E.J., Dawson, R. and Pellymonater, M.A., Forebrain norepinephrine and the selective processing of information, Brain Research, 190 (1980) 569-573.

41 Mackintosh, N.J., A theory of attention: variations in the associability of stimuli with reinforcement, Psychol. Rev. 82 (1974) 274-298

42 Markowitsch, H.J. and Pritzel, M., Learning and the prefrontal cortex of the cat: anatomico-behavioral interrelation, Physiol. Psychol., 4 (1976) 247-261.

43 McFarland, D.J., Kostas, J. and Drew, W.G., Dorsal hippocampal lesions: effects of preconditioning CS exposure on flavour aversion, Behav. Biol., 22 (1978) 398-404.

44 Miller, R., Major psychosis and dopamine: controversial leatures and some suggestions, Psychol. Med., 14 (1984) 
774-789.

45 Moore, J.W., Goodell, N.A. and Solomon, P.R., Central cholinergic blockade by scopolamine and habituation, classical conditioning and latent inhibition of the rabbit's nictitating membrane response, Physiol. Psychol., 4 (1976) 395-399.

46 Numan, R., Ward, C. and Clark, J., Septal lesions and active avoidance performance in rats: effects of differential intra-box cues, Physiol. Behav., 29 (1982) 489-493.

47 Oades, R.D., Search and attention: interactions of the hippocampal-septal axis, adrenocortical and gonadal hormones, Neurosci. Biobehav. Rev., 3 (1979) 31-48.

48 Oades, R.D., Types of memory or attention? Impairments after lesions of the hippocampus and limbic ventral tegmentum, Brain Res. Bull., 7 (1981) 221-226.

49 Oades, R.D., Dopaminergic agonistic and antagonistic drugs in the ventral tegmentum of rats inhibit and facilitate changes of food search behaviour, Neurosci. Lett., 27 (1981) 75-80.

50 Oades, R.D., Attention and Schizophrenia: Neurobiological Bases, Pitman Press, London, 1982, 343 pp.

51 Oades, R.D., The role of noradrenaline in tuning and dopamine in switching between signals in the CNS, Neurosci. Biobehav. Rev., 9 (1985) 261-282.

52 Oades, R.D., Attention deficit disorder with hyperactivity (ADDH): contribution of catecholaminergic activity, Prog. Neurobiol., in press.

53 Oades, R.D., Rea, M. and Taghzouti, K., Modulation of selective processes in learning by neocortical and limbic dopamine: studies of behavioral strategies. In B. Will, P. Schmitt and J. Dalrymple-Alford (Eds.), Brain Plasticity, Learning and Memory, Plenum Press, New York, 1985, pp. 241-251.

54 Oades, R.D., Simon, H., Taghzouti, K. and Le Moal, M., Dopamine sensitive alternation and collateral behaviour in a Y-maze: effects of D-amphetamine and haloperidol, Psychopharmacology, 85 (1985) 123-128.

55 Oades, R.D., Taghzouti, K., Rivet, J.-M., Simon, H. and Le Moal, M., Locomotor activity in relation to dopamine and noradrenaline in the nucleus accumbens, septal and frontal areas: a 6-hydroxydopamine study, Neuropsychobiology, in press.

56 Price, M.T.C. and Fibiger, H.C., Discriminated escape learning and response to electric shock after 6-hydroxydopamine lesions of the nigro-neostriatal dopaminergic projection, Pharmacol. Biochem. Behav., 3 (1975) 285-290.

57 Rickert, T.J., Bennett, T.L., Lane, P.L. and French, J., Hippocampectomy and the attenuation of blocking, Behav. Biol., 22 (1978) 147-160.

58 Rickert, E.J., Lorden, J.F, Dawson, R., Smyly, E. and Callahan, M.F., Stimulus processing and stimulus selection in rats with hippocampal lesions, Behav. Neural Biol., 27 (1979) 454-465.

59 Rickert, E.J., Lorden, J.F., Dawson, R. and Smyly, E., Limbic lesions and the blocking effect, Physiol. Behav., 26 (1981) 601-606.

60 Robbins, T.W. and Everitt, B., Functional studies of the central catecholamines, Int. Rev. Neurobiol., 23 (1982) $245-365$.

61 Robbins, T.W. and Everitt, B., Noradrenaline and selective attention. In B. Will, P. Schmitt and J. Dalrymple-Alford (Eds.), Brain Plasticity, Learning and Memory, Plenum Press, New York, 1985, pp. 219-227.

62 Robbins, T.W. and Koob, G.F., Selective disruption of dis- placement behavior by lesions of the mesolimbic dopamine system, Nature (London), 285 (1980) 409-411.

63 Robbins, T.W., Roberts, D.C.S. and Koob, G.F., Effects of D-amphetamine and apomorphine upon operant behavior and schedule-induced licking in rats with 6-hydroxydopamine-induced lesions of the nucleus accumbens, $J$. Pharmacol. Exp. Ther., 224 (1983) 662-672.

64 Roberts, G.W., Ferrier, I.N., Lee, Y., Crow, T.J., Johnstone, E.C., Owens, D.G.C., Bacarese-Hamilton, A.J., McGregor, G., O’Shaughnessy, D., Polak, J.M. and Bloom, S.R., Peptides: the limbic lobe and schizophrenia, Brain Research, 288 (1983) 199-211.

65 Roland, P.E., Cortical regulation of selective attention in man. A regional cerebral blood flow study, J. Neurophysiol., 48 (1982) 1059-1078.

66 Salafia, W.R. and Allan, A.M., Conditioning and latent inhibition with electrical stimulation of the hippocampus, Pkysiol. Psychol., 8 (1980) 247-253.

67 Scatton, B., Rouquier, L., Javoy-Agid, F. and Agid, Y., Dopamine deficiency in the cerebral cortex in Parkinson's disease, Neurology, 32 (1982) 1039-1040.

68 Seeman, P., Ulpian, C., Bergeron, C., Riederer, P., Jellinger, K., Gabriel, E., Reynolds, G.P. and Tourtelotte, W.W., Bimodal distribution of dopamine receptor densities in brains of schizophrenics, Science, 225 (1984) 728-731.

69 Simon, H., Scatton, B. and Le Moal, M., Dopaminergic A 10 neurones are involved in cognitive functions, Nature (London), 286 (1980) 150-151.

70 Solomon, P.R., The role of the hippocampus in blocking and conditioned inhibition of the rabbit's nictitating membrane response, J. Comp. Physiol. Psychol., 91 (1977) $407-417$.

71 Solomon, P.R., A time and place for everything? Temporal processing views of hippocampal function with special reference to attention, Physiol. Psychol., 8 (1980) 254-261.

72 Solomon, P.R. and Moore, J.W., Latent inhibition and stimulus generalization of the classically conditioned nictitating membrane response in rabbits (Oryctolagus cuniculus) following dorsal hippocampal ablation, J. Comp. Physiol. Psychol., 89 (1975) 1192-1203.

73 Solomon, P.R. and Staton, D.M., Differential effects of microinjections of $\mathrm{D}$-amphetamine into the nucleus accumbens or the caudate putamen on the rat's ability to ignore an irrelevant stimulus, Biol. Psychiat., 17 (1982) 743-756.

74 Solomon, P.R., Kiney, C.A. and Scott, D.R., Disruption of latent inhibition following systemic administration of parachlorphenylalanine (PCPA), Physiol. Behav., 20 (1978) 265-271.

75 Solomon, P.R., Nichols, G.L., Kiernan, J.M., Kamer, R.S. and Kaplan, L.J., Differential effects of lesions in medial and dorsal raphe of the rat: latent inhibition and septohippocampal serotonin levels, J. Comp. Physiol. Psychol., 94 (1980) 145-154.

76 Solomon, P.R., Crider, A., Winkelman, J.W., Turi, A., Kamer, R.M. and Kaplan, L.J., Disrupted latent inhibition in the rat with chronic amphetamine or haloperidol-induced supersensitivity: relationship to schizophrenic attention disorder, Biol. Psychiat., 16(1981) 519-537.

77 Srebro, B., Visual cues in successive position reversals: retention deficits following septal lesions, Physiol. Behav., 12 (1974) 639-646.

78 Swanson, L., The projections of the ventral tegmental area and adjacent regions: a combined fluorescent retrograde tracer and immunofluorescence study in the rat, Brain Res. 
Bull., 9 (1982) 321-353

79 Taghzouti, K., Simon, H., Tazi, A., Dantzer, R. and Le Moal. M., The effect of 6-OHDA lesions of the lateral septum on schedule-induced polydipsia, Behav. Brain Res., 15 (1985) $1-8$.

80 Tsaltas, E., Preston, G.C., Rawlins, J.N.P., Winocur, G. and Gray, J.A., Dorsal bundle lesions do not affect latent inhibition of conditioned suppression, Psychopharmacology, 84 (1984) 549-555.

81 Tweedy, J.R., Langer, K.G. and McDowell, F.H., The effect of semantic relations on the memory deficit associated with Parkinson's disease, J. Clin. Neuropsychol., 4 (1982) 235-247.

82 Warburton, J.W., Memory disturbance and the Parkinson syndrome, Br. J. Med. Psychol., 40 (1967) 169-171.

83 Weiner, I., Lubow, R.E. and Feldon, J., Chronic amphetamine and latent inhibition, Behav. Brain Res., 2 (1981) 285-286.

84 Wolf, M.E., Ryan, J.J. and Mosnaim, A.D., Cognitive functions in tardive dyskinesia, Psychol. Med., 13 (1983) 671-674. 